\title{
Microparticles and Exosomes in Gynecologic Neoplasias
}

\author{
Rienk Nieuwland, Ph.D., 1 Joris A.M. van der Post, M.D., Ph.D., ${ }^{2}$ \\ Christianne A.R. Lok Gemma, M.D., Ph.D., ${ }^{2}$ G. Kenter, M.D., Ph.D., ${ }^{3}$ \\ and Augueste Sturk, Ph.D. 1
}

The publisher regrets an error in the authorship of the above article in Seminars in Thrombosis and Hemostasis, Volume 36, Number 8, 2010, p. 925, and the Table of Contents. The correct author lineup is:

Rienk Nieuwland, Ph.D., ${ }^{1}$ Joris A.M. van der Post, M.D., Ph.D., ${ }^{2}$ Christianne A.R. Lok, M.D., Ph.D., ${ }^{2}$ Gemma Kenter, M.D., Ph.D., ${ }^{3}$ and Augueste Sturk, Ph.D. ${ }^{1}$

Departments of ${ }^{1}$ Clinical Chemistry, ${ }^{2}$ Obstetrics and Gynaecology and ${ }^{3}$ Gynaecological Oncology, Academic Medical Center, Amsterdam, The Netherlands.

Address for correspondence and reprint requests: Rienk Nieuwland, Ph.D., Department of Clinical Chemistry, Academic Medical Center, Meibergdreef 9, 1100 AZ Amsterdam, The Netherlands (e-mail: r.nieuwland@amc.nl).

Hormones, Endocrine Disorders, and Hemostasis; Guest Editors,
Massimo Franchini, M.D., Pier Paolo Vescovi, M.D., Franco Manzato, M.D., and Emmanuel J. Favaloro, Ph.D., M.A.I.M.S.

Semin Thromb Hemost 2011;37:95-95. Copyright (C) 2011 by Thieme Medical Publishers, Inc., 333 Seventh Avenue, New York, NY 10001, USA. Tel: +1(212) 584-4662.

DOI: http://dx.doi.org/10.1055/s-0030-1271292.

ISSN 0094-6176. 